\title{
Heat Recovery System for Reducing Smart Building Carbon Footprint
}

\author{
Yu-Wei Chiu, ${ }^{1}$ Wei-Ming Chiu, ${ }^{1,2}$ and Yean-Der Kuan ${ }^{1,3^{*}}$ \\ ${ }^{1}$ Graduate Institute of Precision Manufacturing, National Chin-Yi University of Technology, \\ No. 57, Sec. 2, Zhongshan Rd., Taiping Dist., Taichung City 41170, Taiwan \\ ${ }^{2}$ Department of Chemical and Materials Engineering, National Chin-Yi University of Technology, \\ No. 57, Sec. 2, Zhongshan Rd., Taiping Dist., Taichung City 41170, Taiwan \\ ${ }^{3}$ Department of Refrigeration, Air Conditioning and Energy Engineering, \\ National Chin-Yi University of Technology, \\ No. 57, Sec. 2, Zhongshan Rd., Taiping Dist., Taichung City 41170, Taiwan
}

(Received January 28, 2019; accepted December 25, 2019)

Keywords: heat recovery system, split-type air conditioner, wall-mounted evaporator, control optimization

Taiwan is located in the subtropical zone where the summers are hot and humid. The demand for comfort and quality of life in this zone is increasing. Air conditioning equipment in Taiwan has transformed from a luxury item into a basic necessity, resulting in a growing demand for small, consumer air conditioning units. Attractive, low-noise, small, and split-type air conditioning systems have become popular in the residential air conditioning equipment market. In this study, we used a heat recovery system to recover heat from air to increase the system hot and cold side efficiency and reduce the carbon footprint of smart buildings. The improved wall mounted evaporator combined with a central monitoring system is different from the typical AC unit evaporator that makes the system much more efficient.

\section{Introduction}

The typical buildings in Taiwan urban areas are high rise. The most common air conditioning system used for residential buildings is the split-type air conditioner where the condenser is placed outside because of the unobstructed air flow for optimum efficiency. The most distinctive feature of the split-type air conditioner is that the evaporator, controller, condenser, compressor, and expansion valve are arranged in separate bodies i.e., outdoor and indoor units. The outdoor and indoor units are connected by a copper tube for the refrigerant to flow in a closed loop system. The proposed system in this study will also follow the split-type air conditioner principle in which the condensing or heat rejection unit is located outside. ${ }^{(1)}$ The indoor unit or evaporator will be a wall-mounted type with modifications and improvements. A galvanized steel pipe will be used as the flowing medium for the hot and cold water. This proposed low-carbon-emission system will be applied in the smart building system. The main

*Corresponding author: e-mail: ydkuan@ncut.edu.tw https://doi.org/10.18494/SAM.2020.2672 
smart building controller will also be connected to the outdoor and indoor air conditioning unit controller. $^{(2,3)}$ The advantage of the split-type air conditioner is that the compressor is located outside, which reduces the noise in the air-controlled space. Another advantage of the split-type system is that it can be installed within a relatively narrow space and has a variety of indoor and outdoor unit appearances that can be matched with the decor of the placement area. The various indoor units include ceiling-concealed, wall-mounted, cassette-type, and standing-type indoor units that can be paired with any outdoor unit. ${ }^{(4-6)}$

\section{Materials and Methods}

The system uses a shipping container as the main housing for the outdoor unit. The shipping container was chosen because it has a global standard for its quality, is easy to use, and can be easily modified. Utilizing shipping containers for temporary construction such as factory storage, temporary buildings, warehouses, shelters, or shop stalls is a common practice in Taiwan. European countries, the United States, and Japan have already applied creativity in using containers as knock-off buildings to another level. Containers have been used as housing, dormitories, hotels, offices, museums, and so forth. In this study, we will focus on transforming a simple shipping container into a low-carbon-emission smart building that will utilize a heat recovery system to increase heat exchanger efficiency as shown in the diagram in Fig. 1. Heat will also be saved and applied to another application such as water heating for general use. A range of modular controls will be used to improve the system efficiency. With the heat recovery system, many more options for the saved energy will open, thus increasing energy savings. ${ }^{(7,8)}$

The heat pump recovery working principle uses the heat pump condenser side to produce hot water as shown in the diagram in Fig. 2. The hot water is stored in a water tank. The heat pump evaporator side is used to produce cold water and store it in a low-temperature water tank. The cold water and hot water are used for cooling and heating, respectively. ${ }^{(9)}$ The refrigerant in the heat recovery system will flow to the heat exchanger connected to the condenser and

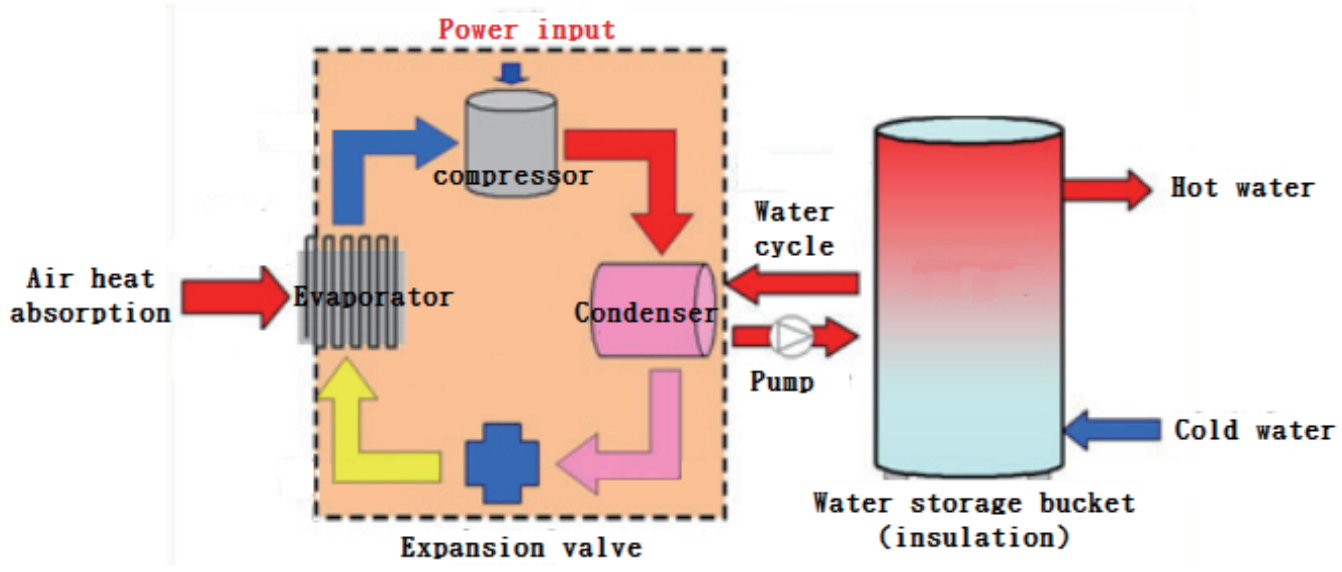

Fig. 1. (Color online) Heat recovery system process. 


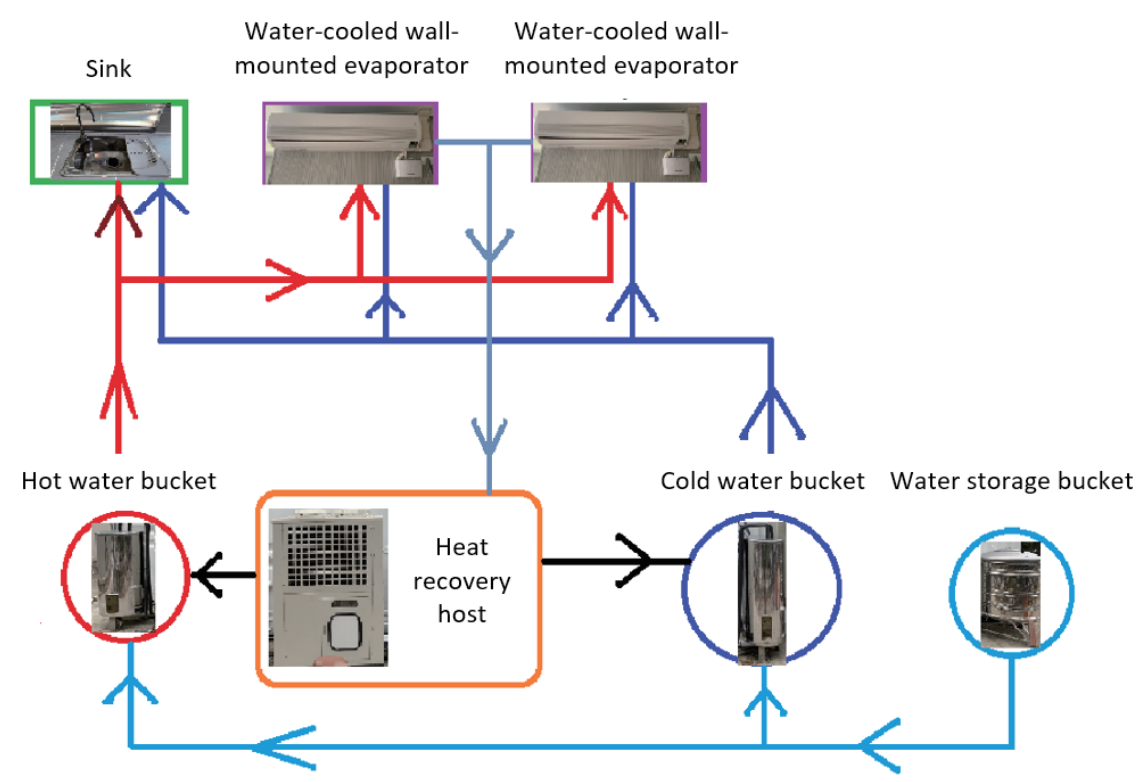

Fig. 2. (Color online) Heat recovery system working diagram.

absorb the excess heat. The heated refrigerant will be transferred to another heat exchanger where it will heat water inside the heat exchanger. After that, the "cooled" refrigerant will flow to another heat exchanger where it will absorb heat from the water on the heat exchanger and decrease the water temperature, thus inducing the cooling effect. That refrigerant will then be transferred to the condenser side and the cycle will start over again. This loop is repeated again and the resulting hot water will be stored inside a hot or water tank with the cold water stored in a cold water tank. The higher the ambient temperature, the higher the heat recovery system efficiency. ${ }^{(10,11)}$

\section{Experimental Rig and Control and Monitoring System}

In this study, we used R-507 refrigerant as the working fluid for the system because it is a suitable refrigerant for medium- to low-temperature applications. The purpose of the proposed device is to create low-temperature water required for air conditioning and then use a frequency drive controller to control the low-temperature water flow to obtain similar energy savings as an inverter air conditioning system. The heat pump heat recovery system (hot water side) will use the heat obtained from the ambient air to increase the temperature of the water and then store the hot water in a tank to be used in hot water applications. Each respective tank will deliver water at a specific temperature according to the control system. During the peak load time, low-temperature water will be used to decrease the room temperature by sending that water to the evaporator. ${ }^{(12-15)}$

By heat recovery with a heat pump, heating water and cooling water can be produced and stored simultaneously. The system has two sets of wall-mounted evaporators. The first 
evaporator set is $4.2 \mathrm{~kW}$ and the second evaporator set is $6.3 \mathrm{~kW}$. Both evaporator sets are water-cooled types, not the traditional refrigerant cooled evaporator as shown in Figs. 3 and 4. The main unit will handle two evaporators. The setup for the heat pump and heat recovery system is shown in Fig. 5, while setup conditions are shown in Table 1. The control board for the system is shown in Fig. 6.

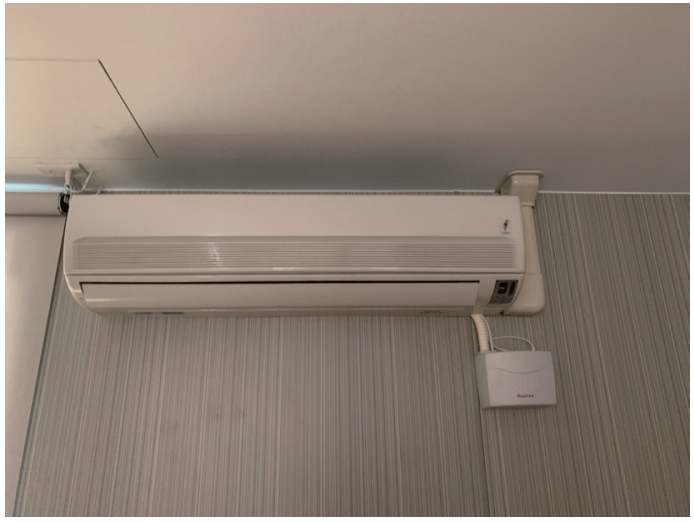

Fig. 3. (Color online) Indoor evaporator unit.

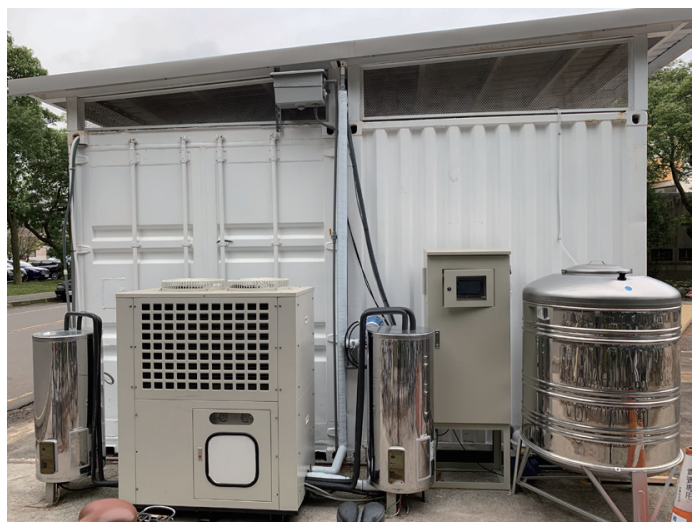

Fig. 5. (Color online) Heat pump and heat recovery system.

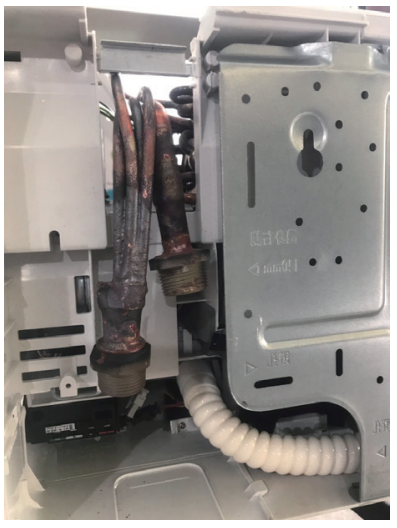

Fig. 4. (Color online) Indoor evaporator unit water distributor pipe.

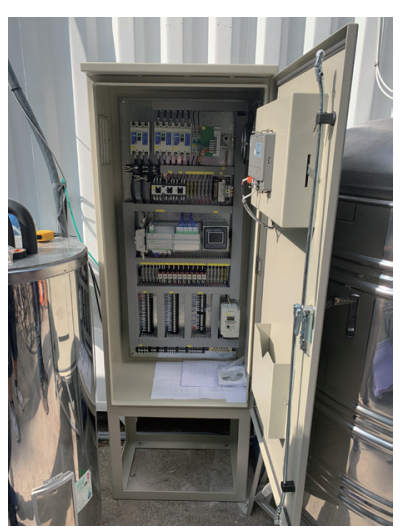

Fig. 6. (Color online) Control panel.

Table 1

Test conditions.

\begin{tabular}{lcc}
\hline \multirow{2}{*}{ Set conditions } & \multicolumn{2}{c}{ Operation mode } \\
\cline { 2 - 3 } & Air-conditioning mode $\left({ }^{\circ} \mathrm{C}\right)$ & Heating mode $\left({ }^{\circ} \mathrm{C}\right)$ \\
\hline Ice water temperature (outlet) & 10 & - \\
Hot water temperature (outlet) & - & 45 \\
Indoor evaporator temperature & 16 & 40 \\
\hline
\end{tabular}


A programmable logic controller (PLC)-based controller is used as the system controller. The control mode is divided into two modes, namely, the cooling and heating modes. Various other features such as rapid cooling, rapid heating, dehumidification, and ventilation are also provided by the control system. The sensors used in the system are an indoor air quality sensor (temperature, humidity, carbon dioxide, three in-one), a water pressure sensor, a water temperature sensor, and a water level sensor as shown in Fig. 7. The specifications of the sensors and controller are shown in Table 2.

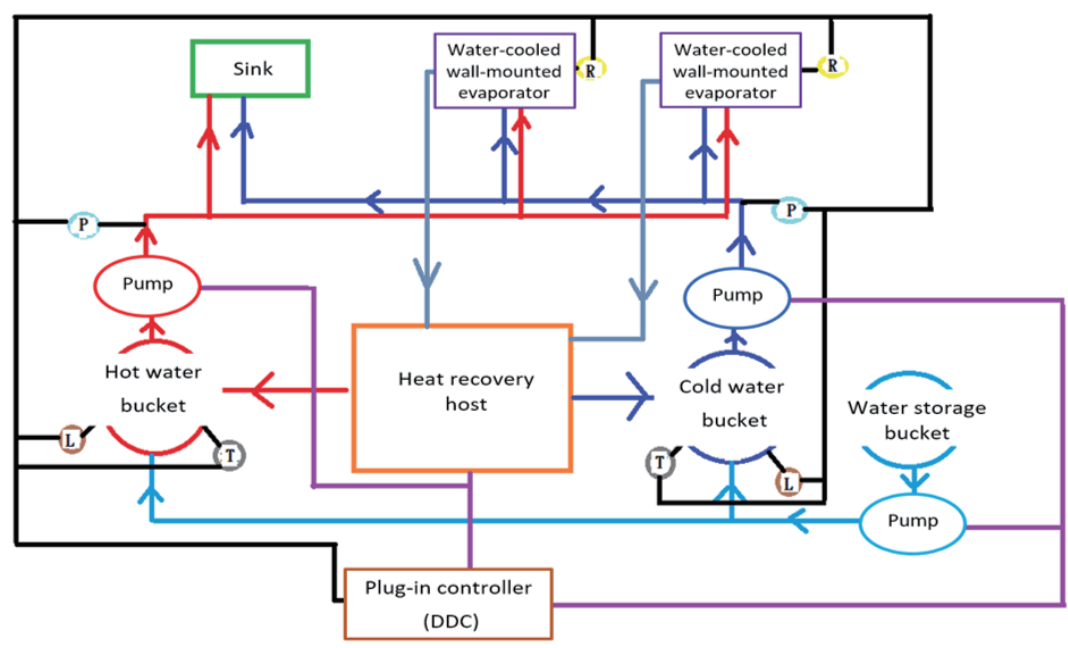

Sensor section:

1. R. : Indoor air quality

(Temperature and humidity carbon dioxide three-in-one sensor)

2. (P): Water pressure difference sensor

3. (T) : Water temperature sensor

4. (D) : Liquid level sensor

Control section:

1. Heat recovery host

2. Pump

3. Water-cooled wall-mounted evaporator

Fig. 7. (Color online) Control diagram.

Table 2

Sensor and controller specifications.

\begin{tabular}{|c|c|c|c|c|}
\hline \multirow{2}{*}{\multicolumn{2}{|c|}{ Parameters }} & \multicolumn{3}{|c|}{ Characteristics } \\
\hline & & Measurement range & Accuracy & Tolerance range \\
\hline \multirow{3}{*}{ Indoor air quality } & Temperature $\left({ }^{\circ} \mathrm{C}\right)$ & $0-80$ & 0.3 & \pm 0.1 \\
\hline & Humidity (\%) & $0-95$ & 3 & \pm 1 \\
\hline & $\mathrm{CO}_{2}(\mathrm{ppm})$ & $0-6000$ & 50 & \pm 10 \\
\hline \multicolumn{2}{|c|}{ Water pressure sensor } & $0-6$ Bar & $0.5 \mathrm{Bar}$ & $\pm 0.5 \%$ \\
\hline \multicolumn{2}{|c|}{ Water temperature sensor } & $-40-133{ }^{\circ} \mathrm{C}$ & $1{ }^{\circ} \mathrm{C}$ & $\pm 0.1{ }^{\circ} \mathrm{C}$ \\
\hline \multicolumn{2}{|l|}{ Water level sensor } & $\begin{array}{l}-10-70{ }^{\circ} \mathrm{C} \\
\text { (used range) }\end{array}$ & $\begin{array}{c}100 \mathrm{M} \Omega \\
\text { (insulation resistance) }\end{array}$ & 0 \\
\hline \multicolumn{2}{|l|}{ Card controller } & Microprocessor 32-bit & $\begin{array}{c}\text { Instruction speed: } 0.065 \mu \mathrm{s} \\
\text { Application instruction speed: } \\
0.642 \mu \mathrm{s}\end{array}$ & $\begin{array}{l}\text { Operation speed: } \\
\qquad 34 \mathrm{~ns}\end{array}$ \\
\hline
\end{tabular}


The indoor evaporator has only four functions, namely, turn-on, turn-off, cooling, and heating. An air quality sensor is placed next to the evaporator. The sensor signal rating is 0-4 $\mathrm{mA}$ and $0-10 \mathrm{~V}$. The controller will read the input from the sensor and send an output signal for the heat pump to produce hot water and cold water. The hot or cold water is then stored in their respective tanks. The temperature sensor inside the water tank will transmit a signal to the controller to determine whether the system should be turned off or the hot/ cold water flow should be bypassed. A water level sensor is also placed inside the tank to transmit a signal to the controller. When the water level is below the set point, the controller will automatically send a signal to the water pump to refill the water tank. A water pressure transducer is installed inside the system pipeline. The signal from the transducer will be used by the controller to determine the water flow volume inside the pipe. The controller will control the pump speed using a frequency driver. By integrating all of these control modes with the main software system, additional features such as rapid heating, rapid cooling, dehumidification, and ventilation are made available.

\section{Results and Discussion}

During these experiments, the pump flow was determined using a signal from the water pressure transducer. The difference between the set point and the actual transducer reading determines the pump frequency. The initial pipeline pressure is 4.63 Bar. The controller sets the pressure to 3.51 Bar. The controller reduces the pump frequency from 59.1 to $44.3 \mathrm{~Hz}$. The decrease in frequency is equal to the proportion of the water pressure, which is $44.3 / 59.1=3.51 / 4.63$ $=0.75$; thus, the energy saving rate is $1-0.75=0.25(25 \%)$, as shown in Fig. 8 .
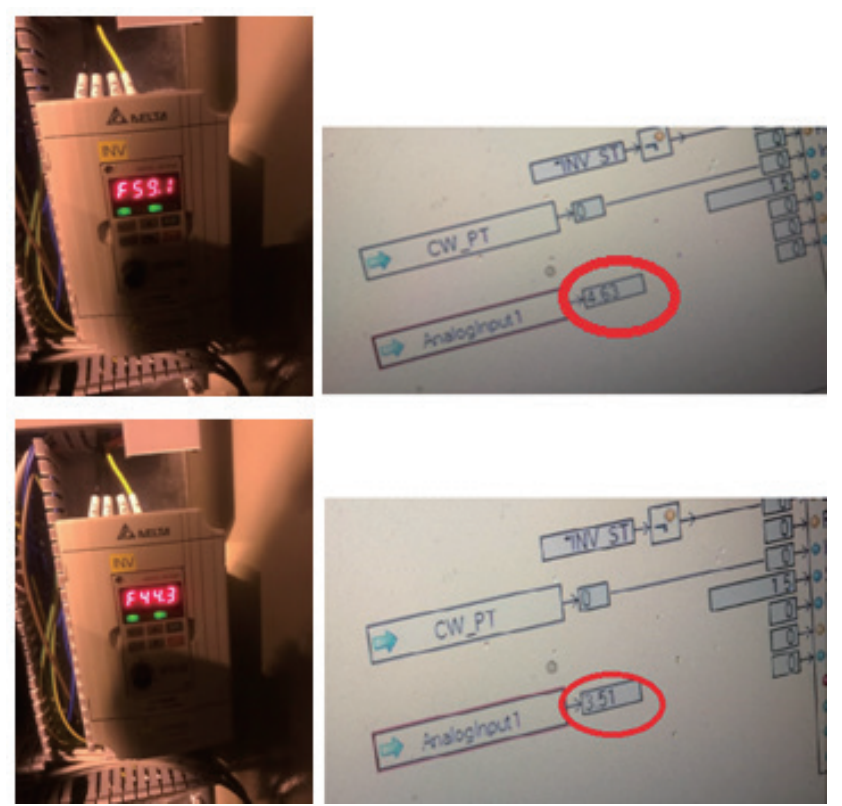

Fig. 8. (Color online) Water pressure-pump frequency difference. 
During the second set of experiments, the heating mode was chosen. The water outlet temperature was set to $45{ }^{\circ} \mathrm{C}$. The indoor evaporator temperature was set to $40{ }^{\circ} \mathrm{C}$. The temperature in the storage tank then increased from 33.3 to $53.5^{\circ} \mathrm{C}$ to achieve the desired setpoint temperature, as shown in Fig. 9.

During the third set of experiments, the cooling mode was chosen. The outlet water temperature was set to $10{ }^{\circ} \mathrm{C}$. The indoor evaporator temperature was set to $16{ }^{\circ} \mathrm{C}$. The water temperature in the storage tank then decreased from 22.4 to $8.2{ }^{\circ} \mathrm{C}$ to maintain the desired set point temperature, as shown in Fig. 10.

The heat recovery system can save $4404.06 \mathrm{kcal} /$ degree $(860 \times 5.69 \times 0.9)$ and use $30 \mathrm{~L}$ of water for the heating mode. The total heat recovered is $75591.9 \mathrm{kcal}, 75591.9 \mathrm{kcal} / 4404.06 \mathrm{kcal}$ $=17.16$ degrees $/$ day $\times 3 \mathrm{NTD} /$ degree $\times 365$ days $=18790.2 \mathrm{NTD} /$ year.

These experiments showed that when the evaporator cooling mode is $10.51 \mathrm{~kW}$, the energy consumed is $2.24 \mathrm{~kW}$. In the heating mode, the evaporator heating capacity is $12.75 \mathrm{~kW}$ and the energy consumed is $2.24 \mathrm{~kW}$.

The compressor used in this system is a $3 \mathrm{HP}$ hermetic compressor. The heat recovery system manages two evaporators simultaneously. The logic controller is added to optimize the control efficiency. The coefficient of performance (COP) for this system is calculated as $10.51 / 2.24=4.45$ for the cooling mode and 12.75/2.24 $=5.45$ for the heating mode [coefficient of performance for heating $(\mathrm{COPH})]$. In the summer, the cooling seasonal performance factor (CSPF) is $12.93 / 2.21=5.85$ and the CSPF is $13.15 / 2.21=5.95$ in the winter.

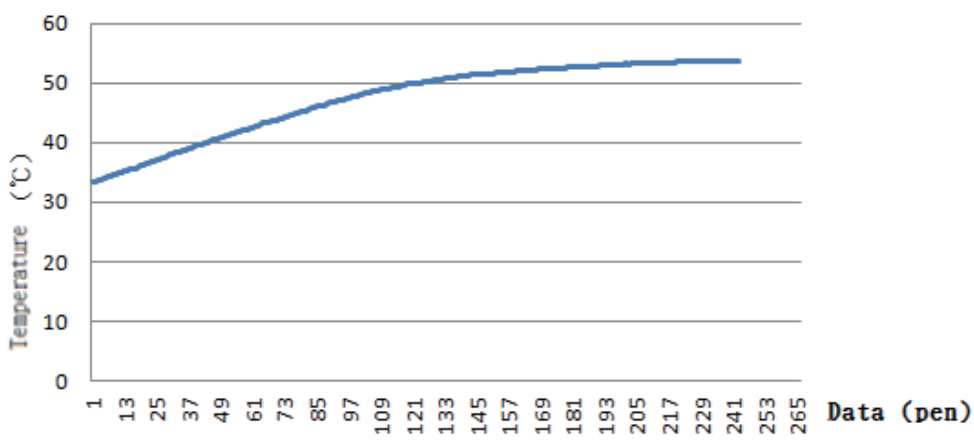

Fig. 9. (Color online) Hot water storage tank temperature.

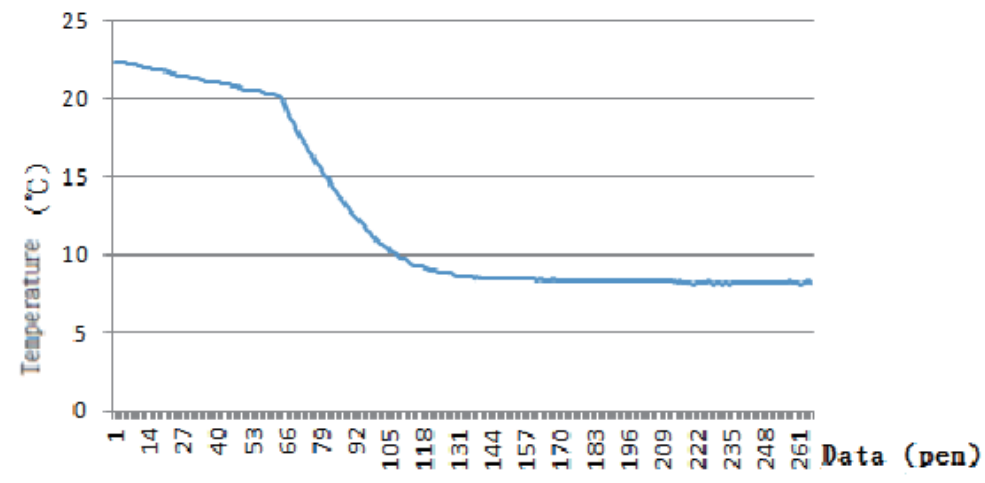

Fig. 10. (Color online) Cold water storage tank temperature. 


\section{Conclusions}

This system uses heat pump heat recovery technology to absorb heat from ambient air and use it to produce hot water and cold water. After the cold or hot water is put into their respective storage thanks, the system can deliver on-site load demand, either heating or cooling, and the water-pump-controlled frequency reduces the system energy usage. The variable water flow is proven to be effective in delivering the required on-site load heating or cooling function.

The typical wall-mounted evaporator uses a direct-expansion refrigerant, while the evaporator developed in this study uses water as its working fluid. This approach is innovative because it is not available in the general market. We hope that the proposed water-cooled evaporator will become more common in the future.

Since the scale of these experiments was small, the control logic algorithm is written to satisfy a small variable control system. The code used in these experiments is not suitable for more complex or larger scale applications. Owing to the nature of the PLC card controller used in this system, rewriting or modifying the current logic and algorithm is possible. By writing it on a different card or using a different controller, this method is open for improvement for later optimization. This also makes it possible for the system to be developed for larger scale or more complex logic applications.

\section{Acknowledgments}

This research was funded by a grant from the Ministry of Science and Technology Project No. MOST 107-3113-E-008-003. We are thankful for support from the Ministry of Science and Technology and National Chin-Yi University of Technology, Refrigeration, Air-Conditioning, and Energy Engineering Department.

\section{References}

A. Hepbasli and Y. Kalinci: Renewable Sustainable Energy Rev. 13 (2009) 1211.

X. Liu, L. Ni, S.-K. Lau, and H. Li: Appl. Therm. Eng. 51 (2013) 698.

X. Liu, L. Ni, S.-K. Lau, and H. Li: Appl. Therm. Eng. 59 (2013) 253.

T. Berntsson: Int. J. Refrig. 25 (2002) 428.

K. J. Chua, S. K. Chou, and W. M. Yang: Appl. Energy 87 (2010) 3611.

6 S. Okamoto: Energy Build. 38 (2006) 121.

7 J. C. Lam and W. W. Chan: Energy Convers. Manage. 44 (2003) 1625.

8 X. Yu, X. Q. Zhai, and R. Z. Wang: Energy Convers. Manage. 51 (2010) 2162.

9 J. Xu, Y. Zhao, Z. Quan, G. Wang, and J. Wang: Appl. Therm. Eng. 141 (2018) 483.

10 Y. M. Li and J. Y. Wu: Energy Build. 42 (2010) 1093.

11 J. Yu, C. Yang, and L. Tian: Energy Build. 40 (2008) 1536.

12 X. Liu, F. Hui, Q. Guo, Y. Zhang, and T. Sun: Energy Build. 111 (2016) 408.

13 C. Liang, X. Wen, X. Zhang, and H. Xiao: ICETCE Conf. (2011) 3166.

14 D. Pamitzki: J. Dyn. Syst. Meas. Contr. 107 (1989) 174.

15 P. Mithraratne, N. E. Wijeysundera, and T. Y. Bong: Int. J. Refrig. 23 (2000) 174. 


\section{About the Authors}

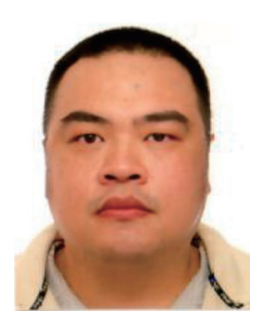

Yu-Wei Chiu received his B.S. degree (2006) and his M.S. degree (2010) from National Chin-Yi University of Technology, Taiwan. He has been a Ph.D. student at the same college since 2014. He has gained a lot of experience in refrigeration engineering since he studied at the Department of Refrigeration, Air Conditioning and Energy Engineering. For the past few years, he has been engaging in the diagnosing of energy saving and energysaving reengineering as well. (jackywei@ncut.edu.tw)

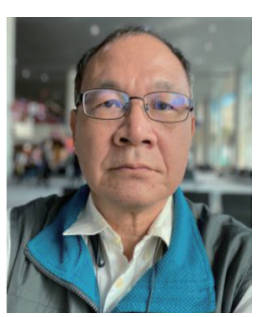

Wei-Ming Chiu received his B.S. degree from Taiwan Institute of Technology, Taiwan, in 1989 and his M.S. and Ph.D. degrees from Taiwan University of Science and Technology, Taiwan, in 1991 and 1998, respectively. From 1998 to 2009, he was an associate professor at National Chin-Yi Institute of Technology, Taiwan. Since 2009, he has been a professor at National ChinYi University of Technology. His research interests are in polymer, phot-elect material, and chemical materials. (cwm@ncut.edu.tw)

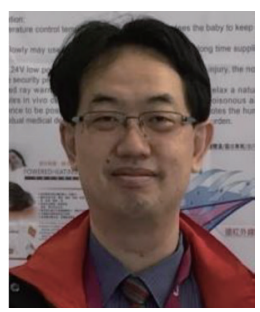

Yean-Der Kuan received his B.S. degree from Tamkang University, Taiwan, in 1991. He received his M.S. degree from Georgia Institute of Technology, USA, in 1996 and his Ph.D. degree from the University of MissouriColumbia, USA, in 2000. From 2001 to 2005, he was as an assistant professor at Taipei City University of Science and Technology, Taiwan. From 2005 to 2007, he was as an associate professor at Taipei City University of Science and Technology, Taiwan. From 2007 to 2010, he was as an associate professor at National Chin-Yi University of Technology, Taiwan. Since 2010, he has been a professor at National Chin-Yi University of Technology, Taiwan. His research interests are in fuel cells, HVAC, energy saving, environmental control, and sensors. (ydkuan@ncut.edu.tw) 